\title{
Bernard Gainot et Vincent Denis (dir.), Un siècle d'ordre public en Révolution (de 1789 à la Troisième République)
}

\section{Michel Biard}

\section{(2) OpenEdition \\ Journals}

\section{Édition électronique}

URL : https://journals.openedition.org/ahrf/11749

DOI : 10.4000/ahrf.11749

ISSN : 1952-403X

Éditeur :

Armand Colin, Société des études robespierristes

Édition imprimée

Date de publication : 1 septembre 2010

Pagination : 211-212

ISBN : 978-2-200-92633-5

ISSN : 0003-4436

\section{Référence électronique}

Michel Biard, «Bernard Gainot et Vincent Denis (dir.), Un siècle d'ordre public en Révolution (de 1789 à

la Troisième République) », Annales historiques de la Révolution française [En ligne], 361 | juillet-

septembre 2010, mis en ligne le 22 mars 2011, consulté le 24 avril 2022. URL : http://

journals.openedition.org/ahrf/11749; DOI : https://doi.org/10.4000/ahrf.11749

Ce document a été généré automatiquement le 24 avril 2022.

Tous droits réservés 


\title{
Bernard Gainot et Vincent Denis (dir.), Un siècle d'ordre public en Révolution (de 1789 à la Troisième République)
}

\author{
Michel Biard
}

\section{RÉFÉRENCE}

Bernard Gainot et Vincent Denis (dir.), Un siècle d'ordre public en Révolution (de 1789 à la Troisième République), Paris, Société des études robespierristes, Collection études révolutionnaires $\mathrm{n}^{\circ}$ 11, 2009, 204 p., ISBN 978-2-908327-69-4, $25 €$

1 Cet ouvrage rassemble les actes d'une journée d'étude tenue en mai 2007 à l'initiative de la Société des études robespierristes, de l'Institut d'histoire de la Révolution française et du Centre de Recherches en histoire du xix siècle (Universités Paris I et Paris IV), ainsi que du laboratoire Collectivités territoriales de la Faculté de Droit et Gestion de l'Université d'Orléans. Après une brève présentation de Bernard Gainot et Vincent Denis, neuf textes se succèdent, les cinq premiers concernant la Révolution française et les quatre suivants le XIX ${ }^{\mathrm{e}}$ siècle (la seconde Restauration, la Révolution de 1848, la Commune de Paris, la gendarmerie au cours de ce siècle). Ils permettent des approches variées et stimulantes dans la mesure où, d'une part, les changements d'échelle sont fréquents dans les analyses proposées, ici un district de Paris, là une ville (Lyon) ou encore un département (le Calvados); d'autre part, les réflexions plus vastes portent sur des questions qui donnent à penser bien au-delà des seules limites chronologiques affichées (la loi martiale et l'état de siège, la répression du brigandage, la gendarmerie).

2 Dans deux textes consacrés aux forces qui contribuent au maintien de l'«ordre ", Bruno Ciotti analyse le rôle de la Garde nationale à Lyon entre 1789 et 1793, tandis 
qu'Aurélien Lignereux consacre son travail à la gendarmerie sous le Consulat. Un des intérêts de la première étude est de montrer très concrètement les obligations de service des gardes nationaux, la fréquence des tours de garde, piquets et autres missions. Fréquence jugée trop lourde par certains, aussi les refus de service se multiplient-ils en 1791, avec des conséquences aggravées sitôt que des volontaires nationaux sont levés parmi les hommes de la Garde nationale. À partir de l'été 1792, celle-ci ne suffit plus pour réprimer les « désordres » lyonnais, tandis que le contrôle de ses bataillons devient un enjeu dans les rivalités qui opposent entre elles les mouvances politiques. Ainsi, en mai 1793, les amis de Chalier prévoient une « sévère purge » de la Garde nationale trop ouvertement liée aux modérés... mais trop tard pour éviter la rébellion de Lyon contre l'autorité de la Convention nationale. De son côté, Aurélien Lignereux développe avec finesse le rôle de la gendarmerie dans la répression du brigandage, le Consulat succédant ici à un Directoire qui n'a pas été la période principale d'affaiblissement de cette force (celle-ci devant plutôt être située en 1793-1794). Si cette étude doit retenir l'attention, force est toutefois de constater que les travaux précédents publiés par l'auteur, ainsi que de multiples recherches récentes sur la gendarmerie, avaient déjà permis de renouveler en grande partie nos connaissances sur ce sujet. D'ailleurs, le fait même que deux autres textes du présent volume soient également consacrés aux gendarmes ( $\mathrm{au}$ XIX ${ }^{\mathrm{e}}$ siècle) témoigne aussi de ce renouvellement. Aurélien Lignereux apporte donc ici une nouvelle pierre à l'édifice.

3 Avec le district parisien de Saint-Roch en 1789-1790, Vincent Denis nous propose, pour sa part, une plongée dans un quartier qui n'est pas forcément le plus tranquille de la capitale, en raison de la présence du Palais-Royal, haut lieu de la fermentation politique. La police que tentent d'y exercer les nouvelles autorités nées de 1789 apparaît vite comme "une police sans policiers ", qui entretient tout d'abord des relations avec les commissaires du Châtelet restés en place (à l'automne 1789, une répartition s'opère, le Châtelet se limitant aux affaires criminelles, la police municipale se concentrant sur les délits susceptibles d'être punis d'amendes ou de détention passagère). La «tranquillité » du district passe par la chasse aux mots susceptibles de créer des maux, puisque plus de la moitié des affaires traitées sont des délits liés à la librairie, la seconde catégorie étant ensuite celle des "propos incendiaires ». Plus de $70 \%$ des cas recensés sont "politiques ", de près ou de loin, et révèlent notamment l'obsession précoce du «complot». Cette "police de la parole » présente toutefois des limites flagrantes et s'efforce de faire le tri entre les "exaltés " et de "simples imprudents ", mais Vincent Denis conclut qu'elle suffit à "désamorcer bien des tensions » en ces années 1789 et 1790. Reste que les affrontements ne sont pas encore suffisamment exacerbés pour que la situation devienne explosive. Et, à ce jeu-là, le cas du Calvados en 1793 est évidemment très différent. Guillaume Mazeau revient dans sa contribution sur des conclusions déjà en partie connues, telles les divisions internes des "fédéralistes " et l'action modératrice des représentants du peuple en mission, notamment Robert Lindet qui préconise lui aussi de séparer les «meneurs » de ceux qui n'ont été qu' «égarés ». Dans ce département, la répression passe avant tout par des arrestations, en nombre limité, et des mesures symboliques. Faut-il pour autant en appeler à une " politique des émotions " (concept qui revient à plusieurs reprises dans ce texte)? Ne faudrait-il pas surtout insister sur les importantes nuances qui existent dans le Calvados pour peu que l'on passe de l'échelle du département à celle des districts et plus encore des communes, et souligner l'importance majeure de l'adoption de la nouvelle Constitution (et de la Déclaration des droits) qui a grandement contribué 
à briser la " rébellion » ? Les travaux d'Anne de Mathan sur Bordeaux et le département de la Gironde ont justement mis à jour de semblables nuances et prouvé que l'adoption de la Constitution avait ôté aux «fédéralistes » une partie de leurs arguments et donc de leur force.

Enfin, Michel Pertué nous offre une longue et passionnante étude sur la loi martiale, l'état de siège et la législation révolutionnaire. Il évoque tout d'abord l'adoption de la loi martiale le 21 octobre 1789, dans le climat tendu qui suit la marche sur Versailles (mais une telle loi est en fait discutée depuis l'été déjà), ainsi que les effets des articles de cette loi parfois flous et complétés par des textes ultérieurs. Sans doute convient-il aussi de souligner que la notion de "moteur" de l'attroupement mérite l'attention, dans la mesure où, en cas de présence d'armes dans la foule, a fortiori en cas de violences, ces meneurs sont tenus pour responsables et risquent la peine de mort (même s'ils n'étaient pas eux-mêmes armés et/ou violents). Parallèlement à la loi martiale, l'Assemblée constituante définit également la notion de crime de «lèsenation", qui conduit à une répression plus spécifiquement politique, là où la loi martiale visait d'abord les attroupements populaires. Avec l'entrée de la France dans la guerre, vient ensuite un troisième moyen de répression extraordinaire, l'état de siège. Initialement état de siège réel (appliqué à une place assiégée), il se double alors d'un état de siège fictif, qui permet la répression contre les adversaires, réels ou supposés, de la Révolution. Ce texte de Michel Pertué présente un triple intérêt: montrer que le recours aux mesures extraordinaires a été omniprésent sous la Révolution, mais en revêtant des formes différentes au fil du temps; proposer des réflexions souvent stimulantes sur la Terreur; enfin, ne pas hésiter à contester et mettre en débat les propositions de nombreux historiens, dans leur diversité, de Patrice Gueniffey à Sophie Wahnich, en passant par Carla Hesse et Anne Simonin. Gageons qu'il ne manquera pas de susciter des commentaires et grâces en soient rendues aux organisateurs de cette journée d'étude qui nous livrent là un riche volume de la Collection études révolutionnaires. 